SIYUAN ZHANG, Graduate Student ${ }^{1}$

E-mail: zhangsiyuan2019@126.com

SHIJUN YU, Ph.D. ${ }^{1}$

E-mail: yushijun2017@163.com

SHEJUN DENG, Ph.D. ${ }^{1}$

(Corresponding author)

E-mail: dsj@yzu.edu.cn

QINGHUI NIE, Ph.D. ${ }^{1}$

(Corresponding author)

E-mail: nieqingh@yzu.edu.cn

PENGPENG ZHANG, Graduate Student ${ }^{1}$

(Corresponding author)

E-mail: zhang.pengpeng@ccdi.com.cn

CHEN CHEN, Ph.D. ${ }^{2}$

(Corresponding author)

E-mail: chenc4@oregonstate.edu

${ }^{1}$ Yangzhou University

University South Road, No. 88, Yangzhou, Jiangsu, China

2 Oregon State University

1500 SW Jefferson Way, Corvallis, OR 97331, USA
Science in Traffic and Transport Original Scientific Paper Submitted: 1 Mar. 2019 Accepted: 4 Sep. 2019

\title{
DYNAMIC DEMAND FORECAST AND ASSIGNMENT MODEL FOR BIKE-AND-RIDE SYSTEM
}

\begin{abstract}
Bike-and-Ride (B\&R) has long been considered as an effective way to deal with urbanization-related issues such as traffic congestion, emissions, equality, etc. Although there are some studies focused on the $B \& R$ demand forecast, the influencing factors from previous studies have been excluded from those forecasting methods. To fill this gap, this paper proposes a new B\&R demand forecast model considering the influencing factors as dynamic rather than fixed ones to reach higher forecasting accuracy. This model is tested in a theoretical network to validate the feasibility and effectiveness and the results show that the generalised cost does have an effect on the demand for the B\&R system.
\end{abstract}

\section{KEY WORDS}

Bike-and-Ride; dynamic demand; generalised cost; user equilibrium model; Frank-Wolfe algorithm;

\section{INTRODUCTION}

The high level of personal motorisation brings pressure not only to urban traffic but also to the environment and energy [1]. In the past decades, many countries have taken measures to mitigate the pressure, such as developing bike-sharing systems, public transit systems, Park-and-Ride (P\&R) systems and Bike-and-Ride (B\&R) systems [2].

Among those environmentally friendly transportation systems, B\&R system turns out to be faster, more convenient and with a lower cost [3]. As one part of the B\&R system, public transport has long been regarded as an effective way of alleviating urban traffic problems for its advantages because of big capacity, low pollution, low energy consumption, and high traffic efficiency. However, the public transport also has its drawbacks, such as its poor flexibility and low ability to provide door-to-door service [4-7]. As the other part of a B\&R system, bicycle is substantially faster than walking and more flexible than public transport, but it is not efficient for long-distance trips [8]. Therefore, the B\&R system, which combines these two travel modes, provides a way to utilize their advantages and to alleviate the drawbacks from either single system [9-11]. Encouraging people to choose B\&R system will have a positive effect in releasing urban transport pressure, reducing traffic pollution, energy consumption and land resource occupation $[12,13]$.

\section{LITERATURE REVIEW}

Because of its significant effect on alleviating urban traffic pressure, B\&R has attracted a lot of attention. The existing research focused on B\&R can be summarized into three main aspects: (1) the analysis of factors affecting the mode choice of $B \& R$ and rider behaviour; (2) policies and programs for facility and configuration optimization; (3) demand forecast.

Many studies focused on analysing factors affecting mode choice of B\&R. R. Kager, Bertolini [14] provided suggestions on combining bicycle and public transport in a broader perspective, such as higher speed for the bicycle lane and higher public transport capacity. Puello [15] incorporated latent variables and 
psychometric data to capture relatively intangible factors that influence the mode choice. Krizek and Stonebraker [16] analysed factors influencing the integration of bicycle and transit, such as transit mode, access, egress distance, and trip purpose. Chen [17] considered the factors affecting the B\&R mode choice from three angles: socio-economic characters, trip features and residents' perceptions for the service level of B\&R mode. Previous studies also found that bicycle facility is the main factor that influences the mode choice between bicycle and other modes [18-20]. Some researchers explored and found that the weather is also an important factor in the mode choice [21-23]; for instance, the bicycle users may be more sensitive to the rainfall and temperature than other mode users; however, bicycle-friendly facilities can attract riders back to riding. Heinen [24] conducted further exploratory research and found that residents always emphasise the convenience level, the cost and health benefits when deciding on the transportation mode.

Regarding mode choice analysis, Taylor [25] employed a stated preference survey to explore the residents' choice preferences among private cars, P\&R mode and the B\&R mode. Wardman [26] adopted a multinomial logit model based on the revealed preference and stated preference data, and found that protected non-motorised road or a completely segregated bike path, may encourage more residents to choose the bicycle. There were also some studies that employed the social equilibrium models and mathematical network models [27-29] to explore the B\&R mode in terms of bicycle parking locations, bicycle network, route choice, bicycle activity patterns, etc. Yang [30] presented a mode choice model for B\&R. Aziz [31] estimated a random parameter (mixed) logit model for active transportation (walking and bicycle) choices for work trips in the New York City. Chan [32] used a Structural Equation Model (SEM) to formulate the relationship between the individual's behavioural intention of using a public bicycle and its influencing factors.

For improving the B\&R system, researchers suggested strategies to enhance the ratio of using $B \& R$ mode, such as ensuring the parking safety and convenience at the public transport sites, taking the bicycle into public transport management system, giving the bicyclists more right-of-way [33, 34]. Pucher [35] pointed out that the key factors to improve the using rate of $B \& R$ are the service level of bicycle transfer facilities and the safety of bicycle parking. Chen [36] explored the correlation between the level of traffic stress (LTS) and bicycle crash by a mixed logit framework and they found that LTS has an effect on injury severity. Pucher [35], Lumsdon [37], and Martens [38] proposed new policies for authorities to improve the use of bicycles, such as infrastructure provisions, supportive land use planning, and restrictions on car use. Another study conducted by Pucher and Buehler [39] found that even though the temperature is much lower in Canada than in America, the usage frequency of bicycles in Canada is higher. Safer biking conditions, and more extensive biking facilities and training programs in Canada may account for this.

A macroscopic forecast method was employed by Zhang [40] to study the situation of bicycle transfer in Beijing and successfully predicted bicycle transfer demand of parking the bike. Caulfield [41] used stated preference survey to do some research on B\&R. Recently, with the dramatic increase of sharing bike and rental bike programs in cities, there are many studies focused on demand prediction [42, 43]. For instance, a binary logit model of public bicycles was established by Wu [44] and Chen [45] to predict the demand of public bicycles of the rail transit station. Wardman [46] developed a choice model to identify the factors influencing the rate of cycling to work in the UK and the authors used this model to forecast future trends in urban commuting mode share. Mi [47] considered two factors (travel time and travel cost) in a utility function to build a logit model to get the possibility of bike transfer.

Previous research mentioned above suggested that even though a lot of work has been done in the B\&R topic, current research is limited to analysing the factors affecting the traveller's choice and the policies of promoting the B\&R system. Although there are some studies focused on the B\&R demand forecast, the influencing factors from previous studies are excluded from those forecasting methods. Specifically, the obtained demand was fixed in previous forecasting studies without considering those influencing factors. However, with the change of these influencing factors, the traveller's choice of whether to choose B\&R travel mode also varies. In other words, the travel demand of B\&R mode changes dynamically rather than being fixed. Thus, there is still a gap in the demand forecast for the B\&R system with taking the influencing factors into consideration.

To fill this gap, this paper proposes a new demand forecast model considering the demand of $B \& R$ mode as dynamic rather than fixed to reach a higher forecasting accuracy. With specific analysis factors that lead to changes in demand, the entire $B \& R$ travel chain was divided into three main processes, and the factors in each process are converted into generalised costs. In this way, the generalised cost is a comprehensive indicator which leads to dynamic changing in demand. The UE model and the adaptive Frank-Wolf algorithm are employed to distribute the dynamic demand of B\&R in the network. The proposed non-fixed travel demand in the forecast can provide more realistic prediction and help rational configuration of the B\&R facilities (bus stops and bicycle parking lots, etc.) and increase the efficiency of the system. 
The following part of this paper is organized as follows: Section 3 explains how to represent the dynamic demand of $B \& R$ in the model and introduces the UE model and adaptive Frank-Wolfe algorithm to distribute the dynamic demand of B\&R in the network. In Section 4, a theoretical B\&R network was designed to validate the feasibility and effectiveness of the proposed framework. Finally, the concluding remarks and limitations are discussed in Section 5.

\section{METHODOLOGY}

\subsection{Combined network of B\&R}

Public transport and bicycles play different roles in urban transportation due to the difference in their capacity and accessibility. Their roles in urban transportation are shown in Figure 1. These two transport modes supplement and collaborate with each other in urban transportation and form the B\&R mode. Based on their different functions, the B\&R network can be defined as a combined network composed of the public transport network and the bicycle network.

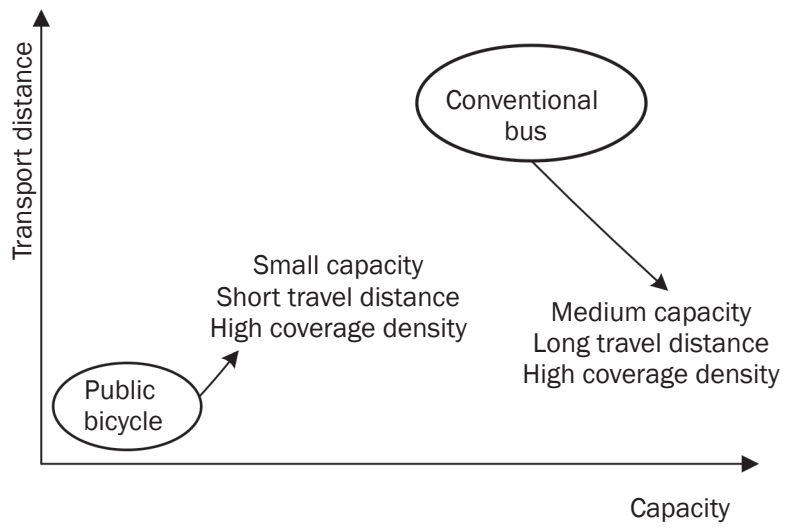

Figure 1 - Different roles in urban transportation

In order to provide a widely applicable model, the conventional bus network and bicycle network were chosen as representatives of the public transport network and the transfer network. The transfer network is an abstract network which mainly reflects the mobility of travellers from the start location of the trip to the bus stop (or from the bus stop to the travel destination). A bicycle and public transport combined network (Figure 2) was simulated as $\mathrm{G}(\mathrm{N}, \mathrm{A})$, in which $\mathrm{N}$ is a collection of nodes and $A$ is a collection of network edges. The nodes consist of conventional bus stop N1 and transfer site N2. The transfer site is where a traveller changes their travel mode from bicycle to public transport. The public transport network edge A1, transfer network edge A2 are included in the network edges. The public transport network and the transfer network are connected via transfer sites.
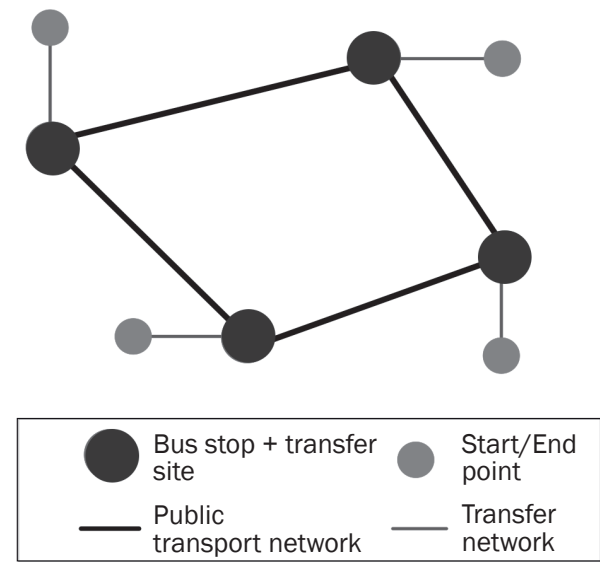

Figure 2 - Bicycle and public transportation network

\subsection{Generalised cost}

Factors influencing the decision making are usually translated into path impedance or utility. In this study, the generalised cost (negative effect) is used to describe the path impedance. Consequently, the dynamic demand of $B \& R$ can be expressed as the response of $B \& R$ demand to generalised cost.

From the perspective of a complete $B \& R$ travel chain, the entire process can be divided into three main parts: the sub-process of public transport (taking conventional bus as an example), the sub-process of the bicycle, and the sub-process of the transfer between public transport and bicycle. The generalised cost of B\&R mode will be analysed from these three sub-processes, respectively. The total generalised cost of the B\&R travel is the sum of generalised costs in each stage.

\section{The sub-process of the conventional bus}

The generalised cost of the conventional bus consists of the travel time in the bus, waiting time at the bus stop, the impedance for the crowded ride environment and the bus fare. In the algorithm, it can be expressed as follows:

$u_{p}^{b}=\alpha_{T}^{b} T_{p}^{b}+\alpha_{W}^{b} W_{p}^{b}+u_{o}^{b}$

where $u_{p}^{b}$ is the generalised cost of a conventional bus on route $p ; \alpha_{T}^{b}$ is the cost of travel time on the bus; $\alpha_{W}^{b}$ is the cost of the waiting time for a conventional bus; $T_{p}^{b}$ is the travel time for the conventional bus on route $p ; W_{p}^{b}$ is the waiting time for the conventional bus on route $p ; u_{o}^{b}$ is the fare for the conventional bus for all routes; $u_{p}^{b}$ is the generalised cost for the conventional bus on route $p$.

For the network description, the Bureau of Public Roads (BPR) function [48], which is set by the U.S. Federal Highway Administration, is often used as an impedance of the road segment. This function can also be used in the B\&R research. In general, the road 
traffic condition and the passenger flow are the two main factors related to the conventional bus travel time. Therefore, it can be shown as:

$T_{p}^{b}=t_{p}^{0}\left[1+\alpha_{1}\left(\frac{v_{i l}+v_{i l}^{\prime}}{K_{b}^{l}}\right)\right], i \in S$

where $T_{p}^{b}$ is the travel time for the conventional bus on route $p ; i$ is a random bus station on route $p ; t_{p}^{0}$ is the initial travel time of conventional bus which is affected by the road condition, and it can be obtained from the actual GPS data of public transportation vehicles; $v_{i l}$ is the number of passengers who get on the bus before bus stop $i$ and get off the bus after bus stop $i$; $v_{i l}^{\prime}$ is the number of passengers who get on the bus after bus stop $i ; K_{b}^{l}$ is the capacity of the conventional bus line $l$; $\alpha_{1}$ and $\beta_{1}$ are the travel time parameters of the bus. $S$ is the set of bus stations.

According to the Welding model $[49,50]$, when the passenger arrives at the bus stop randomly, the passenger's expected waiting time is the sum of the half of the bus headway and the coefficient of variation of the bus headway. The waiting time at the bus stop can be shown as:

$W_{p}^{b}=\frac{0.5}{f_{s}^{l}} 1+\left(C V^{2}\right)$

where $W_{p}^{b}$ is the waiting time at the bus stop; $f_{s}^{\prime l}$ is the departure frequency of line $l$ at station $s$. $C V$ is the headway variation coefficient. The headway time variation coefficient $C V$ can be obtained by calculating the sample mean and biased deviation based on the actual headway distribution. $C V$ can be predicted by assuming a distribution function.

\section{The sub-process of the bicycle}

Compared to the conventional buses, bicycles can serve immediately but need to consume some physical strength. Considering the factors that mainly affect the traveller's bicycle choice, such as cycling time, rental expenses and physical energy consumption, the generalised cost of bicycle travel on route $p$ can be expressed as:

$u_{p}^{p b}=\alpha_{t}^{p b} T_{p}^{p b}+\alpha_{y}^{p b} Y_{p}^{p b}+u_{0}^{p b}$

where $u_{p}^{p b}$ is the generalised cost of bicycle travel on route $p ; \alpha_{t}^{p b}$ is the cycling cost; $T_{p}^{p b}$ is the travel time on a bicycle on route $p ; \alpha_{y}^{p b}$ is the parameter of physical energy consumption; $Y_{p}^{p b}$ is the parameter of fatigue caused by cycling on route $p ; u_{0}^{p b}$ is the fee for renting a bicycle for all routes.

Travel time $\left(T_{p}^{p b}\right)$ can be obtained from the length of route and the riding speed:

$T_{p}^{p b}=\frac{L_{p}}{V_{p}^{p b}}$

where $T_{p}^{p b}$ is the travel time of riding on route $p ; L_{p}$ is the length of riding on route $p ; V_{p}^{p b}$ is the average speed of riding on route $p$.
The consumption of physical energy can be estimated according to its relationship with the travel time. As the travel time increases, the physical consumption also increases. The physical fatigue parameter can be expressed as a function of the travel time. In this paper, the Binomial function studied by Gong [51] is employed:

$Y_{p}^{p b}=f\left(T_{p}^{p b}\right)=\tau_{1} T_{p}^{p b}+\tau_{2}\left(T_{p}^{p b}\right)^{2}$

where $Y_{p}^{p b}$ is the consumption of physical energy; $\tau_{1}$ and $\tau_{2}$ are parameters of the function and can be determined according to a specific situation. It can be seen from the function that the physical consumption value increases with the increase of the distance. This can explain why bicycles are not suitable for long-distance trips.

The sub-process of transfer

In the transfer stage, the transfer time includes the walking time, the waiting time and the delay. The waiting time has been considered in the above two sub-processes. The walking time and the delay are two main factors that need to be discussed in this sub-process. The walking time refers to the consumption of time in the process of completing the transfer between the bicycle and the public transport on foot. The delay represents the uncertainty that may be caused by the mode conversion and the subjective reluctance of the traveller, which is the inherently general cost of the transfer. The generalised cost for transfer is:

$u_{p}^{t}=\alpha_{z}^{t} Z_{p}^{t}+u_{0}^{t}$

where $u_{p}^{t}$ is the generalised cost; $\alpha_{z}^{t}$ is the unit time value; $Z_{p}^{t}$ is the walking time during the transfer process; $u_{0}^{t}$ is the inherent generalised cost of transfer between bicycle and bus; $u_{p}^{t}$ is the generalised cost for transfer on route $p$.

The assignment method for this study is based on the route rather than the road segments. A variety of public transportation modes can be included in one route. This paper only selects the conventional bus as a generalised research object. The function of the generalised cost of route $\mathrm{p}$ for an arbitrary Origin Destination pair $(\mathrm{OD})(r, s)$ is:

$u_{p}^{r s}=\sum_{a \in A_{t} \cup A_{d}} \delta(p, a) u_{a}$

where $u_{p}^{r s}$ is the generalised cost of route $p$ for an arbitrary OD pair $r$ and $s$; when the road segment $a$ is on route $p$ which is between OD pairs $r$ and $s, \delta(p, a)=1$, otherwise, $\delta(p, a)=0 ; u_{a}$ is the generalised cost for road augment; $A_{t}$ represents the public transport network and $A_{d}$ is the bicycle network.

\subsection{Model description}

The forecast and assignment of $B \& R$ demand are the basis for optimizing the configuration of the $B \& R$ system. The generalised cost of B\&R will affect the 
travel demand of B\&R mode and make the travel flow shift in the transportation network. Therefore, the dynamics of the travel demand is directly related to the generalised cost. In order to optimize B\&R network configuration and improve traffic efficiency, it is very necessary to build a dynamic traffic assignment model with taking the generalised cost into consideration. The UE model which is based on the Wardrop's first principle [52] has been used in the traffic network analysis. In the traditional traffic assignment issue, the travel demand is always assumed to be known and fixed. However, it is difficult to accurately describe the actual demand in the network. In this paper, the UE model is employed as the basic model and takes the generalised cost as a dynamic factor to build a more accurate demand forecast model for the B\&R system.

Based on the analysis of the generalised cost, the change of the generalised cost is the change of impedance. With the increase of impedance, the probability that the traveller chooses to travel by bicycles and public transportation becomes smaller. Conversely, with the reduction of impedance, the travellers are more inclined to choose the B\&R mode, so the demand for $B \& R$ becomes larger. Consequently, the form of a neg ative exponential function was used to represent this feature.

$Q_{r}=Q \cdot e^{-\alpha \mu}$

where $Q$ is the maximum potential travel demand; $Q_{r}$ is the actual travel demand under a certain generalised travel cost; $\mu$ is the generalised cost in a trip; $\alpha$ is a dynamic demand parameter, which reflects the sensitivity of the traveller to the generalised cost; the specific value of a parameter can generally be determined through investigation.

A higher traffic demand brings busy traffic and busy traffic means higher route impedance. When the route impedance increases, the traveller may cancel some of the originally planned trips or change their destination, so the traffic demand between the original OD pairs will be reduced accordingly. The travel demand and the route impedance interact with each other, and eventually, they will reach an equilibrium state.

In this issue, the amount of travel between two OD pairs, $(r, s)$, is actually related to the impedance between the two points. The reason may be that the traveller with a travel plan changes their plan or cancels the plan directly, due to the fact that the available attraction points are all difficult to reach. Consequently, it not only affects the assignment of travel demand, but also the generation of travel. For the basic UE model, it is assumed that the amount of travelling between each pair of the OD pairs is fixed. In other words, it would not be affected by the impedance. In contrast, the UE model with considering of generalised cost treats that demand as a variable.
The relationship between the travel demand of a pair of OD points and the route impedance can be described by a function:

$q_{r s}=D_{r s}\left(u_{r s}^{\min }\right) \quad \forall r, s$

where $D_{r s}$ is a demand function with $u_{r s}^{\min }$ as a variable; $u_{r s}^{\min }$ is the minimum impedance from $r$ to $s ; q_{r s}$ is the travel demand between $r$ and $s$.

Generally speaking, the demand function between all OD pairs has a substantially consistent form, except that the specific parameters of the heterogeneous pairs are different. These parameters are determined by the size of the population, their income, and car ownership in a specific trip generation zone, as well as the employment status, the ability to attract activities such as shopping and tourism. According to the dynamic demand analysis in the previous section, the travel demand function takes the form of a negative index:

$q_{r s}=Q_{r s} \cdot \exp \left(-a \cdot u_{r s}^{\min }\right)$

where $Q_{r s}$ is a potential demand function, and parameter, $a$ is related to the traffic analysis zone and used to characterise land use characteristics. Additionally, the demand function should be bounded because the amount of population and vehicles in a zone are limited. There is a constraint for this function:

$0 \leq q_{r s} \leq Q_{r s}$

Similar to the normal equilibrium model, the UE problem of dynamic demand can be described by the following model:

$$
\begin{aligned}
& \min : Z(X, q)=\sum_{a} \int_{0}^{x_{a}} u_{a}(w) d w-\sum_{r s} \int_{0}^{q_{r s}} D_{r s}^{-1}(w) d w \\
& \text { s.t. } 0 \leq q_{r s}<Q_{r s} \\
& f_{k}^{r s} \geq 0, \quad \forall r, s \\
& \sum_{k} f_{k}^{r s}=q_{r s}=\forall r, s \\
& x_{a}=\sum_{r, s} \sum_{k} f_{k}^{r s} \cdot \delta_{a, k}^{r s}, \forall a \\
& \delta_{a, k}^{r s}= \begin{cases}1, & \text { section } a \text { is on path } k \text { between } r \text { and } s \\
0, & \text { others }\end{cases}
\end{aligned}
$$

where $x_{a}$ is the traffic flow on section $a ; u_{a}(w)$ is the function of impedance; $q_{r s}$ is the travel demand between $r$ and $s ; D_{r s}^{-1}(w)$ is the inverse function of travel demand; $Q_{r s}$ is a potential demand function; $f_{k}^{r s}$ is the traffic flow on the $k$-th path between $r$ and $s ; \delta_{a, k}^{r s}$ is a section path-related variable.

\subsection{Adopted Frank-Wolfe algorithm}

Frank-Wolfe algorithm is employed to optimise the solution in the model as described by Cho et al. [53]. Firstly, the objective function of the model is changed into another form with the route flow as a variable. The algorithm is also assumed to have been iterated 
$n$ times. Corresponding to the traffic flow of route $f^{n}$, the traffic flow of road segments and travel demand are $x^{n}$ and $q^{n}$, respectively. In order to obtain the iteration direction of the objective function, the model was decomposed into multiple independent sub-problems corresponding to each OD point pair. When all sub-problems are solved, the corresponding road segment flow and the OD demand are generated. Optimal iteration step value $\lambda$ can be obtained based by dichotomy based on the traffic flow of the road segment and OD demand:

$$
\min : Z(\lambda)=\sum_{a} \int_{0}^{x_{a}^{n}+\lambda\left(y_{a-a}^{n}-x_{a}^{n}\right)} u_{a}(w) d w-\sum_{r s} \int_{0}^{q_{r s}^{n}+\lambda\left(\left(p_{s s}^{n}-q_{r s}^{n}\right)\right.} D_{r s}^{-1}(w) d w
$$

where parameter $\lambda$ meets the restriction: $0 \leq \lambda \leq 1 ; x_{a}^{n}$ is road segment flow after $n$ times iteration; $y_{a}^{n}$ is additional traffic after $n$ times iteration; $q_{r s}^{n}$ is travel demand after $n$ times iteration; $p_{r s}^{n}$ is additional demand after $n$ times iteration.

The updated traffic flow of the road segment and OD demand can be obtained by:

$$
x_{a}^{n+1}=x_{a}^{n}+\lambda\left(y_{a}^{n}-x_{a}^{n}\right)
$$

$q_{r s}^{n+1}=q_{r s}^{n}+\lambda\left(p_{r s}^{n}-q_{r s}^{n}\right)$

The algorithm for solving the user equilibrium model of the B\&R network under dynamic demand is as follows and the process is shown in Figure 3:

1) Initialization. In this step, we initialize $n=1$. Firstly, the network is extended to a combined network of bus networks and bicycle networks. Then, a set of road segment traffic flow, $\left\{x_{a}^{0}, \forall a\right\}$, and OD demand, $\left\{q_{r s^{\prime}}^{1} \forall a, s\right\}$, that satisfy the constraints of the model need to be set. For example, $\left\{x_{a}^{0}=0, \forall a\right\}$ was assumed in this paper, then, determine $q_{r s}^{1}$ based on the maximum OD travel demand $Q_{r s}\left(\right.$ e.g. $\left.q_{r s}^{1}=\frac{Q_{r s}}{2}\right)$. Finally, according to All or Nothing (AON) algorithm, $q_{r s}^{1}$ is assigned on the network with a road segment traffic flow $\left\{x_{a}^{0}, \forall a\right\}$.

2) Update the impedance for each edge of the network. Calculate the value of $D_{r s}^{-1}\left(q_{r s}^{n}\right)$, based on the function $u_{a}^{n}=u_{a}\left(x_{a}^{n}\right) \forall a$.

3) Next iteration. Calculate the shortest path and minimum impedance $c_{r s}^{n}$ between OD pairs $(r, s)$ based on $\left\{u_{a}\left(x_{a}^{n}\right): \forall a\right\}$, and consider the following

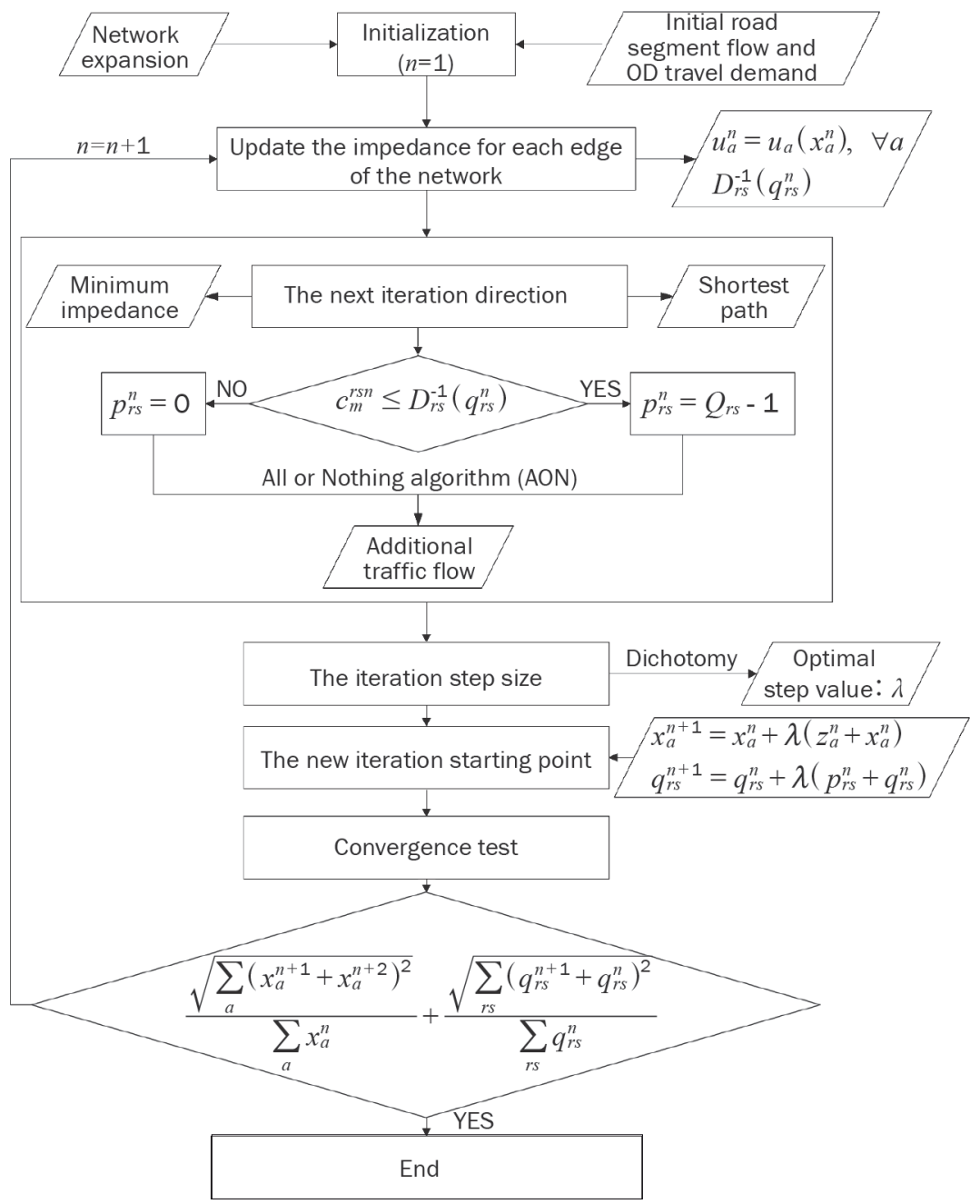

Figure 3 - Process of algorithmic solution 
situation to determine the additional traffic: (i) $c_{m}^{r s n} \leq D_{r s}^{-1}\left(q_{r s}^{n}\right)$ let $p_{r s}^{n}=Q_{r s}-1$ and assign $p_{r s}^{n}$ to the shortest path with All or Nothing (AON) algorithm and correspondingly increase the additional traffic $z_{a}^{n}$ of each road segment on the shortest path; (ii) $c_{m}^{r s n}>D_{r s}^{-1}\left(q_{r s}^{n}\right)$ : let $p_{r s}^{n}=0$ and, consequently, the additional traffic of each road segment on the shortest path is unchanged.

4) Determine the step value for iteration. Use the dichotomy to find the optimal value $\lambda$.

5) Determine the new iteration starting point with the following function: $x_{a}^{n+1}=x_{a}^{n}+\lambda\left(z_{a}^{n}-x_{a}^{n}\right), q_{r s}^{n+1}=q_{r s}^{n_{+}}$ $\lambda\left(p_{r s}^{n}-q_{r s}^{n}\right)$.

6) Test convergence. If the result meets the following restriction, the calculation would be stopped; else return to Step 2 and let $n=n+1$.

$$
\frac{\sqrt{\sum_{a}\left(x_{a}^{n+1}-x_{a}^{n}\right)^{2}}}{\sum_{a} x_{a}^{n}}+\frac{\sqrt{\sum_{r s}\left(q_{r s}^{n+1}-q_{r s}^{n}\right)^{2}}}{\sum_{r s} q_{r s}^{n}}<\varepsilon
$$

where $\varepsilon$ is a predetermined small positive number.

7) End of the algorithm.

\section{MODEL SIMULATION}

\subsection{The description of simulated B\&R network}

In this simulation, a simulated B\&R network was constructed. Based on the simplified public transport network, a B\&R network was constructed as shown in Figure 4. The example network consists of 17 nodes, 20 edges, and 8 OD pairs. The bus lanes in this network are all bidirectional. The square node is the starting point, and the round node is the bus stop. To simplify the structure of the network and the process of calculation, this paper makes some assumptions as follows: i) The distance between the bicycle parking lot and the bus stop (starting/end point) is 0 .

ii) The capacity of the road between the two bus stops is 700 persons/hour and the capacity of the transfer road (the road between the start point/end point and the bus stop) is 3,000 persons/hour.

iii) The initial impedance of roads between bus stops is assumed in Table 1.

iv) The potential travel demand between each OD pair and the dynamic demand parameter a for the function of dynamic demand, $Q_{r}=Q \cdot \exp (-a \cdot t)$, is also assumed in Table 2.

\subsection{Simulation}

Based on the analysis in the previous chapter, the model can be executed in the following steps.

As shown in Figure 4, the original OD points are the nodes that coincide with the bus stop. Therefore, it is necessary to extend those nodes to obtain new OD points and make assumptions about whether the traveller would use a bicycle as a transfer vehicle at these new OD points (Table 3).

Based on the extended nodes, the impedance and capacity assumed previously, the extended adjacency matrix can be obtained (Table 4).

Table 1 - Initial impedance of roads between bus stops

\begin{tabular}{|c|c|c|c|c|c|c|c|c|c|}
\hline Node & 1 & 2 & 3 & 4 & 5 & 6 & 7 & 8 & 9 \\
\hline 1 & 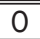 & 2 & - & 2 & - & - & - & - & - \\
\hline 2 & 1 & 0 & 4 & - & 3 & - & - & - & - \\
\hline 3 & - & 3 & 0 & - & - & 2 & - & - & - \\
\hline 4 & 3 & - & - & 0 & 1 & - & 4 & - & - \\
\hline 5 & - & 2 & - & 2 & 0 & 2 & - & 1 & - \\
\hline 6 & - & - & 3 & - & 3 & 0 & - & - & - \\
\hline 7 & - & - & - & 3 & - & - & 0 & 5 & - \\
\hline 8 & - & - & - & - & 2 & - & 4 & 0 & 2 \\
\hline 9 & - & - & - & - & - & 3 & - & 2 & 0 \\
\hline
\end{tabular}

Table 2 - Assumed parameters in this model

\begin{tabular}{||l||c|c|c|c|c|c|c|c||}
\hline \hline Start point & 1 & 2 & 3 & 4 & 6 & 7 & 8 & 9 \\
\hline End point & 9 & 8 & 7 & 6 & 4 & 3 & 2 & 1 \\
\hline Potential demand & 1,000 & 900 & 800 & 950 & 880 & 920 & 700 & 960 \\
\hline Dynamic demand parameter $(a)$ & 0.01 & 0.01 & 0.01 & 0.01 & 0.01 & 0.01 & 0.01 & 0.01 \\
\hline
\end{tabular}

Table 3 - Original OD point and extended node

\begin{tabular}{||l|c|c|c|c|c|c|c|c||}
\hline Original OD point & 1 & 2 & 3 & 4 & 6 & 7 & 8 & 9 \\
\hline Extended node & 10 & 11 & 12 & 13 & 14 & 15 & 16 & 17 \\
\hline Bicycle & 1 & 0 & 1 & 1 & 0 & 1 & 1 & 0 \\
\hline Impedance & 1 & 3 & 1 & 1 & 3 & 1 & 1 & 3 \\
\hline Capacity & 3,000 & 3,000 & 3,000 & 3,000 & 3,000 & 3,000 & 3,000 & 3,000 \\
\hline
\end{tabular}

Note: The value for the bicycle is defined in that if a traveler uses bicycle as transfer vehicle, its value is 1 , otherwise, its value is 0. 
Table 4 - Extended adjacency matrix

\begin{tabular}{||c|c|c|c|c|c|c|c|c|c|c|c|c|c||}
\hline Node & 1 & 2 & 3 & 4 & 5 & 6 & 7 & 8 & 9 & 10 & 11 & 12 & 13 \\
\hline \hline 1 & 0 & 2 & 0 & 2 & 0 & 0 & 0 & 0 & 0 & 1 & 0 & 0 & 0 \\
\hline 2 & 1 & 0 & 4 & 0 & 3 & 0 & 0 & 0 & 0 & 0 & 3 & 0 & 0 \\
\hline 3 & 0 & 3 & 0 & 0 & 0 & 2 & 0 & 0 & 0 & 0 & 0 & 1 & 0 \\
\hline 4 & 3 & 0 & 0 & 0 & 1 & 0 & 4 & 0 & 0 & 0 & 0 & 0 & 1 \\
\hline 5 & 0 & 2 & 0 & 2 & 0 & 2 & 0 & 1 & 0 & 0 & 0 & 0 & 0 \\
\hline 6 & 0 & 0 & 3 & 0 & 3 & 0 & 0 & 0 & 2 & 0 & 0 & 0 & 0 \\
\hline 7 & 0 & 0 & 0 & 3 & 0 & 0 & 0 & 5 & 0 & 0 & 0 & 0 & 0 \\
\hline 8 & 0 & 0 & 0 & 0 & 2 & 0 & 4 & 0 & 2 & 0 & 0 & 0 & 0 \\
\hline 9 & 0 & 0 & 0 & 0 & 0 & 3 & 0 & 2 & 0 & 0 & 0 & 0 & 0 \\
\hline 10 & 1 & 0 & 0 & 0 & 0 & 0 & 0 & 0 & 0 & 0 & 0 & 0 & 0 \\
\hline 11 & 0 & 3 & 0 & 0 & 0 & 0 & 0 & 0 & 0 & 0 & 0 & 0 & 0 \\
\hline 12 & 0 & 0 & 1 & 0 & 0 & 0 & 0 & 0 & 0 & 0 & 0 & 0 & 0 \\
\hline 13 & 0 & 0 & 0 & 1 & 0 & 0 & 0 & 0 & 0 & 0 & 0 & 0 & 0 \\
\hline
\end{tabular}

Note: Some nodes have been omitted due to layout reasons

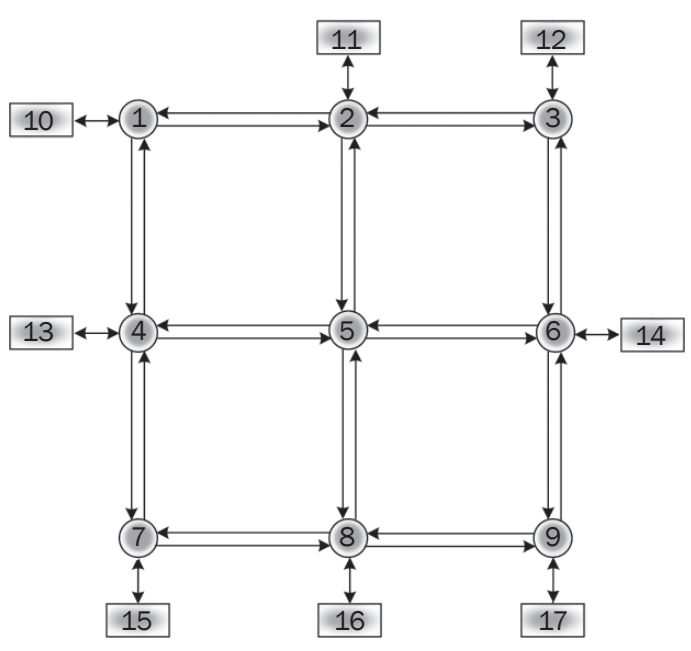

Figure 4 - Combined network of bus and bicycle

Table 5 - The shortest path and smallest impedance

\begin{tabular}{|c|c|c|c||}
\hline$r$ & $s$ & The shortest path & $\begin{array}{c}\text { The smallest } \\
\text { impedance }\end{array}$ \\
\hline 10 & 17 & $10-1-4-5-8-9-17$ & 10 \\
\hline 11 & 16 & $11-2-5-8-16$ & 8 \\
\hline 12 & 15 & $12-3-6-9-8-7-15$ & 12 \\
\hline 13 & 14 & $13-4-5-6-14$ & 7 \\
\hline 14 & 13 & $14-6-5-4-13$ & 9 \\
\hline 15 & 12 & $15-7-4-5-6-3-12$ & 11 \\
\hline 16 & 11 & $16-8-5-2-11$ & 8 \\
\hline 17 & 10 & $17-9-8-5-2-1-10$ & 11 \\
\hline \hline
\end{tabular}

According to the extended adjacency matrix and extended capacity matrix, together with the function of impedance and traffic flow, $t=W \cdot\left(1+0.15 \cdot\left(\frac{X_{1}}{C_{\max }}\right)^{4}\right)\left(X_{1}=0\right)$, the impedance matrix of road segment can be obtained (Table 4).

Based on the impedance matrix of the road segment, OD points and Dijkstra's algorithm, the shortest path and the smallest impedance can be obtained (Table 5).

Based on the dynamic demand function, $Q_{r}=Q \cdot \exp (-a \cdot t)$, where $a$ is the dynamic demand parameter, $t$ is the smallest impedance, the actual travel demand can be obtained (Table 6).

Then, the All or Nothing (AON) algorithm was employed to assign the actual demand to the shortest path. Then, the assigned travel flow after the first assignment process can be obtained (Table 7).

The next job is updating the impedance of each segment to find the following iteration direction, and determining the addition flow based on different constraints. The iteration step size is determined by using the dichotomy. Following these, the new iteration start point can be obtained.

Finally, with the end of the iterations and convergence test, the final assignment result can be obtained (Tables 8-10). The traffic demand of B\&R with considering the generalised cost can be assigned as shown in Figure 5.

Table 6 - Result of dynamic demand

\begin{tabular}{||l||c|c|c|c|c|c|c|c||}
\hline \hline Start point - end point & $10-17$ & $11-16$ & $12-15$ & $13-14$ & $14-13$ & $15-12$ & $16-11$ & $17-10$ \\
\hline$Q$ & 1,000 & 900 & 800 & 950 & 880 & 920 & 700 & 960 \\
\hline Smallest impedance $(t)$ & 10 & 8 & 12 & 7 & 9 & 11 & 8 & 11 \\
\hline Dynamic demand parameter $(a)$ & 0.01 & 0.01 & 0.01 & 0.01 & 0.01 & 0.01 & 0.01 & 0.01 \\
\hline$Q_{r}$ & 904.8 & 830.8 & 709.5 & 885.8 & 804.3 & 824.2 & 646.2 & 860.0 \\
\hline
\end{tabular}

Note: $A$ unified value for a is assumed as 0.01 . 
Table 7 - Assigned travel flow of the first assignment process

\begin{tabular}{||c|c|c|c|c|c|c|c|c|c|c|c||}
\hline \hline Node & 1 & 2 & 3 & 4 & 5 & 6 & 7 & 8 & 9 & 10 & 11 \\
\hline \hline 1 & 0 & 0 & 0 & 904.8 & 0 & 0 & 0 & 0 & 0 & 860.0 & 0 \\
\hline 2 & 860.0 & 0 & 0 & 0 & 830.8 & 0 & 0 & 0 & 0 & 0 & 646.2 \\
\hline 3 & 0 & 0 & 0 & 0 & 0 & 709.5 & 0 & 0 & 0 & 0 & 0 \\
\hline 4 & 0 & 0 & 0 & 0 & $2,614.8$ & 0 & 0 & 0 & 0 & 0 & 0 \\
\hline 5 & 0 & $1,506.2$ & 0 & 804.3 & 0 & $1,709.9$ & 0 & $1,735.6$ & 0 & 0 & 0 \\
\hline 6 & 0 & 0 & 824.2 & 0 & 804.3 & 0 & 0 & 0 & 709.5 & 0 & 0 \\
\hline 7 & 0 & 0 & 0 & 824.2 & 0 & 0 & 0 & 0 & 0 & 0 & 0 \\
\hline 8 & 0 & 0 & 0 & 0 & $1,506.2$ & 0 & 709.5 & 0 & 904.8 & 0 & 0 \\
\hline 9 & 0 & 0 & 0 & 0 & 0 & 0 & 0 & $1,569.5$ & 0 & 0 & 0 \\
\hline 10 & 904.8 & 0 & 0 & 0 & 0 & 0 & 0 & 0 & 0 & 0 & 0 \\
\hline 11 & 0 & 830.8 & 0 & 0 & 0 & 0 & 0 & 0 & 0 & 0 & 0 \\
\hline \hline
\end{tabular}

Note: Some nodes have been omitted due to layout reasons

Table 8 - Final assignment of traffic flow of road segment

\begin{tabular}{||c|c|c|c|c|c|c|c|c|c|c|c||}
\hline \hline Node & 1 & 2 & 3 & 4 & 5 & 6 & 7 & 8 & 9 & 10 & 11 \\
\hline \hline 1 & 0 & 182.5 & 0 & 665.3 & 0 & 0 & 0 & 0 & 0 & 588.1 & 0 \\
\hline 2 & 820.2 & 0 & 96.1 & 0 & 654.9 & 0 & 0 & 0 & 0 & 0 & 342.9 \\
\hline 3 & 0 & 256.8 & 0 & 0 & 0 & 243.1 & 0 & 0 & 0 & 0 & 0 \\
\hline 4 & 78.4 & 0 & 0 & 0 & $1,358.4$ & 0 & 241.2 & 0 & 0 & 0 & 0 \\
\hline 5 & 0 & 923.6 & 0 & 614.4 & 0 & 916.9 & 0 & $1,086.6$ & 0 & 0 & 0 \\
\hline 6 & 0 & 0 & 449.1 & 0 & 612.9 & 0 & 0 & 0 & 235.6 & 0 & 0 \\
\hline 7 & 0 & 0 & 0 & 520.2 & 0 & 0 & 0 & 0 & 0 & 0 & 0 \\
\hline 8 & 0 & 0 & 0 & 0 & 915.3 & 0 & 233.7 & 0 & 534.4 & 0 & 0 \\
\hline 9 & 0 & 0 & 0 & 0 & 0 & 15.6 & 0 & 805.2 & 0 & 0 & 0 \\
\hline 10 & 537.2 & 0 & 0 & 0 & 0 & 0 & 0 & 0 & 0 & 0 & 0 \\
\hline 11 & 0 & 551.3 & 0 & 0 & 0 & 0 & 0 & 0 & 0 & 0 & 0 \\
\hline
\end{tabular}

Table 9 - Final OD demand

\begin{tabular}{|l||c|c|c|c|c|c|c|c||}
\hline \hline Start Point & 10 & 11 & 12 & 13 & 14 & 15 & 16 & 17 \\
\hline End Point & 17 & 16 & 15 & 14 & 13 & 12 & 11 & 10 \\
\hline Demand & 877.29 & 821.73 & 706.76 & 861.39 & 801.497 & 800.19 & 635.69 & 839.77 \\
\hline
\end{tabular}

Table 10 - Final minimum impedance

\begin{tabular}{||l||c|c|c|c|c|c|c|c||}
\hline \hline Start Point & 10 & 11 & 12 & 13 & 14 & 15 & 16 & 17 \\
\hline End Point & 17 & 16 & 15 & 14 & 13 & 12 & 11 & 10 \\
\hline Minimum Impedance & 13.224 & 9.187 & 12.516 & 9.888 & 9.436 & 14.094 & 9.733 & 13.516 \\
\hline
\end{tabular}

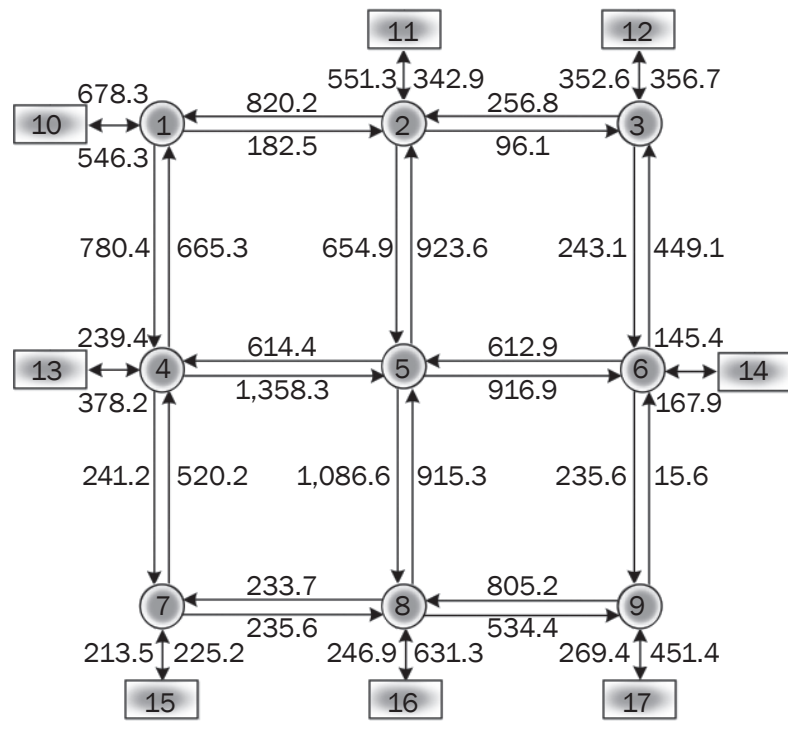

Figure 5 - Optimized traffic flow assignment

\section{CONCLUSION}

This study proposes a dynamic demand forecast and assignment model to predict the demand of the $B \& R$ system more accurately, help rationally configure the B\&R facilities (bus stops and bicycle parking lots, etc.) and increase the efficiency of the system. In this paper the B\&R process has been divided into three main sub-processes and the effective factors in each sub-process have been transferred into the generalised cost so that the change of the B\&R demand was reflected by the change of generalised cost. For modelling this process, this paper introduced a UE model that adopted the Frank-Wolfe algorithm to optimize the solution in the model. Finally, the proposed method was verified by a simulation on a theoretical network. The research framework reflects the response of the B\&R demand to generalised cost more realistically by the non-fixed demand forecasting process, which could help decision makers and engineers to design the B\&R facilities without unnecessary losses. 
There are also some limitations in this work, (1) it only considers the conventional buses as representative public transport in the B\&R system that is composed of many kinds of traffic modes in reality; (2) it does not consider all the factors that have an impact on the generalised costs, other important factors such as distance from origin to bus stop, delay and frequency of public transport that can also make difference to the generalised cost. Future studies can extend to the dynamic demand of the B\&R focus on those domains.

\section{ACKNOWLEDGEMENTS}

This research was funded by the Yangzhou University Graduate International Academic Exchange Fund Project. This work was partially supported by the Science and Technology Program of MOHURD (Ministry of Housing and Urban-Rural Development of China) (N0.2015-K5-005) and the Zhenjiang Key Research and Development Program of China (NO. SH2017047).

作者: 张思远, 于世军, 邓社军, 聂庆慧, 张鹏鹏, 陈晨

\section{自行车和公共交通联合出行动态需求预测和分配模} 型

\section{摘要:}

自行车和公共交通联合出行 $(B \& R)$ 一直以来都被认为 是解决诸如城市交通拥堵、尾气排放、出行公平等问题的 有效途径。尽管许多学者在 $B \& R$ 的需求预测方面进行了大 量的研究, 但是所用的需求预测模型中缺少对影响出行者 $B \& R$ 方式选择的影响因素的考虑。为了提高需求预测的准 确性, 在分析影响出行者 $B \& R$ 方式选择因素的基础上, 本 文将 $B \& R$ 的需求视为动态变化的而非固定的量, 提出了一 个新的 $B \& R$ 动态需求预测和分配模型。为验证模型的可行 性和有效性, 本文将该模型在抽象网络中进行了测试, 结 果表明广义成本确实对 $B \& R$ 方式的需求产生了影响。

关键词: 自行车与公共交通联合出行; 动态交通需 求; 广义费用; 用户均衡模型; FRANK-WOLFE算 法;

\section{REFERENCES}

[1] Xi Z, Jingchu C, Chutao C. The Bike-and-ride Research Based on Low Carbon Consideration at Urban Rail Transit Station. Advanced Materials Research. 2014 Nov 5; 2408-2413.

[2] Qin H, Gao J, Kluger R, Wu YJ. Effects of perception on public bike-and-ride: A survey under complex, multifactor mode-choice scenarios. Transportation Research Part F: Traffic Psychology and Behavior. 2018 Apr 30;54: 264-75.

[3] Yang L, Wang Y. Bike-and-Ride Behavior Study in Economic and Technological Development Zone in Xi'an. Procedia - Social and Behavioral Sciences. 2014 Jul 14;138: 168-73.

[4] Albalate D, Bel G. Tourism and urban public transport: Holding demand pressure under supply constraints. Tourism Management. 2010 Jun 1;31(3): 425-33.
[5] Purifoye GY. Transporting Urban Inequality Through Public Transit Designs \& Systems. City \& Community. 2017 Dec;16(4): 364-8.

[6] Zhao L, Shen L. The impacts of rail transit on future urban land use development: A case study in Wuhan, China. Transport Policy. 2019;81: 396-405.

[7] Brons M, Nijkamp P, Pels E, Rietveld P. Efficiency of urban public transit: A meta analysis. Transportation. 2005 Jan 1;32(1): 1-21.

[8] Martens K. The bicycle as a feedering mode: experiences from three European countries. Transportation Research Part D: Transport and Environment. 2004 Jul 1;9(4): 281-94.

[9] Tang G, Keshav S, Golab L, Wu K. Bikeshare Pool Sizing for Bike-and-Ride Multimodal Transit. IEEE Transactions on Intelligent Transportation Systems. 2018 Jul;19(7): 2279-89.

[10] Jingxu C, Xuewu C, Wei W, Baol F. The demand analysis of bike-and-ride in rail transit stations based on revealed and stated preference survey. Procedia - Social and Behavioral Sciences. 2013 Nov 6;96: 1260-8.

[11] Chan H, Zhi-yun Z. People's Intention towards Public Bicycle System in Wuhan. In: $20158^{\text {th }}$ International Symposium on Computational Intelligence and Design (ISCID), 12-13 Dec. 2015, Hangzhou, China. IEEE; 2016. p. 148-151.

[12] Willis DP, Manaugh K, El-Geneidy A. Uniquely satisfied: Exploring cyclist satisfaction. Transportation Research Part F: Traffic Psychology and Behavior. 2013 May 1;18: 136-47.

[13] Fishman E, Washington S, Haworth N. Barriers and facilitators to public bicycle scheme use: A qualitative approach. Transportation Research Part F: Traffic Psychology and Behaviour. 2012 Nov 1;15(6): 686-98.

[14] Kager R, Bertolini L, Te Brömmelstroet M. Characterisation of and reflections on the synergy of bicycles and public transport. Transportation Research Part A: Policy and Practice. 2016 Mar 1;85: 208-19.

[15] Puello LL, Geurs K. Modelling observed and unobserved factors in cycling to railway stations: application to transit-oriented-developments in the Netherlands. European Journal of Transport and Infrastructure Research. 2015 Jan 1;15(1).

[16] Krizek KJ, Stonebraker EW. Bicycling and transit: A marriage unrealized. Transportation Research Record. 2010 Jan;2144(1): 161-7.

[17] Chen YA, Jian LU, Wei WA, Qian WA. A study on the influencing factors of bicycle transportation based on individual mode choice. Journal of Transportation Systems Engineering and Information Technology. 2007;4: 131-7.

[18] Pei M, Haiyan W. Research on the Bicycle Transfer Rail Traffic Behavior Mechanism and Model. Journal of Beijing University of Civil Engineering and Architecture. 2011;2: 36-40.

[19] Advani M, Tiwari G. Bicycle-As a feeder mode for bus service. In: Velo Mondial Conference: Third Global Cycling Planning Conference, Cape Town, South Africa. 2006 Mar.

[20] Shaheen SA, Guzman S, Zhang H. Bikesharing in Europe, the Americas, and Asia: Past, present, and future. Transportation Research Record. 2010 Jan;2143(1): 159-67. 
[21] Brandenburg C, Matzarakis A, Arnberger A. Weather and cycling-a first approach to the effects of weather conditions on cycling. Meteorological Applications. 2007 Mar 1;14(1): 61-7.

[22] Flynn BS, Dana GS, Sears J, Aultman-Hall L. Weather factor impacts on commuting to work by bicycle. Preventive Medicine. 2012 Feb 1;54(2): 122-4.

[23] Pucher J, Buehler R. Why Canadians cycle more than Americans: a comparative analysis of bicycling trends and policies. Transport Policy. 2006 May 1;13(3): 265-79.

[24] Heinen E, Maat K, Van Wee B. The role of attitudes toward characteristics of bicycle commuting on the choice to cycle to work over various distances. Transportation Research Part D: Transport and Environment. 2011 Mar 1;16(2): 102-9.

[25] Taylor D, Mahmassani H. Analysis of stated preferences for intermodal bicycle-transit interfaces. Transportation Research Record: Journal of the Transportation Research Board. 1996 Jan 1;1556: 86-95.

[26] Wardman M, Tight M, Page M. Factors influencing the propensity to cycle to work. Transportation Research Part A: Policy and Practice. 2007 May 1;41(4): 339 50.

[27] Fukuda D, Morichi S. Incorporating aggregate behavior in an individual's discrete choice: An application to analyzing illegal bicycle parking behavior. Transportation Research Part A: Policy and Practice. 2007 May 1;41(4): 313-25.

[28] Lin JR, Yang TH. Strategic design of public bicycle sharing systems with service level constraints. Transportation Research Part E: Logistics and Transportation Review. 2011 Mar 1;47(2): 284-94.

[29] Vogel P, Greiser T, Mattfeld DC. Understanding bike-sharing systems using data mining: Exploring activity patterns. Procedia - Social and Behavioral Sciences. 2011 Jan 1;20: 514-23.

[30] Yang L, Wang Y. Bike-and-Ride Behavior Study in Economic and Technological Development Zone in Xi'an. Procedia - Social and Behavioral Sciences. 2014 Jul 14;138: 168-73.

[31] Aziz HA, Nagle NN, Morton AM, Hilliard MR, White DA, Stewart RN. Exploring the impact of walk-bike infrastructure, safety perception, and built-environment on active transportation mode choice: a random parameter model using New York City commuter data. Transportation. 2018 Sep 1;45(5): 1207-29.

[32] Chan H, Zhi-yun Z. People's Intention towards Public Bicycle System in Wuhan. In: $20158^{\text {th }}$ International Symposium on Computational Intelligence and Design (ISCID), 12-13 Dec. 2015, Hangzhou, China. IEEE; 2016. p. 148-151.

[33] Yang L, Wang Y. Bike-and-Ride Behavior Study in Economic and Technological Development Zone in Xi'an. Procedia - Social and Behavioral Sciences. 2014 Jul 14;138: 168-73.

[34] Pucher J, Komanoff C, Schimek P. Bicycling renaissance in North America?: Recent trends and alternative policies to promote bicycling. Transportation Research Part A: Policy and Practice. 1999 Sep 1;33(7-8): 625-54.

[35] Pucher J, Dill J, Handy S. Infrastructure, programs, and policies to increase bicycling: an international review.
Preventive Medicine. 2010 Jan 1;50: S106-25.

[36] Chen C, Anderson JC, Wang H, Wang Y, Vogt R, Hernandez S. How bicycle level of traffic stress correlate with reported cyclist accidents injury severities: A geospatial and mixed logit analysis. Accident Analysis \& Prevention. 2017 Nov 1;108: 234-44.

[37] Lumsdon L, Tolley R. The National Cycle Strategy in the UK: to what extent have local authorities adopted its model strategy approach?. Journal of Transport Geography. 2001 Dec 1;9(4): 293-301.

[38] Martens K. Promoting bike-and-ride: The Dutch experience. Transportation Research Part A: Policy and Practice. 2007 May 1;41(4): 326-38.

[39] Pucher J, Buehler R. Why Canadians cycle more than Americans: a comparative analysis of bicycling trends and policies. Transport Policy. 2006 May 1;13(3): 265-79.

[40] Zhang J, Ren F, Liu X, Shi Y. Transfer Analysis of Bike to Public Transit in Beijing. China Journal of Highway and Transport. 1995;8. Chinese.

[41] Caulfield B, Brick E, McCarthy OT. Determining bicycle infrastructure preferences-A case study of Dublin. Transportation Research Part D: Transport and Environment. 2012 Jul 1;17(5): 413-7.

[42] Kang Z, Zuo Y, Huang Z, Zhou F, Chen P. Research on the Forecast of Shared Bicycle Rental Demand Based on Spark Machine Learning Framework. In: $201716^{\text {th }}$ International Symposium on Distributed Computing and Applications to Business, Engineering and Science (DCABES), 13-16 Oct 2017, AnYang, China. IEEE; 2017. p. 219-222.

[43] Feng Y, Wang S. A forecast for bicycle rental demand based on random forests and multiple linear regression. In: 2017 IEEE/ACIS 16 $6^{\text {th }}$ International Conference on Computer and Information Science (ICIS), 2426 May 2017, Wuhan, China. IEEE; 2017. p. 101-105.

[44] Wu Z, Fan Y, Tao J, Zhang J. Key Laboratory of Road and Traffic Engineering in the Ministry of Education, Tongji University; Shanghai Urban Construction Design and Research Institute; Bike-and-Ride Demand Forecasting in Urban Rail Transit Station. Journal of Wuhan University of Technology (Transportation Science \& Engineering). 2013;5.

[45] Jingxu C, Xuewu C, Wei W, Baol F. The demand analysis of bike-and-ride in rail transit stations based on revealed and stated preference survey. Procedia - Social and Behavioral Sciences. 2013 Nov 6;96: 1260-8.

[46] Wardman M, Tight M, Page M. Factors influencing the propensity to cycle to work. Transportation Research Part A: Policy and Practice. 2007 May 1;41(4): 339-50.

[47] Mi W. Study on the Bike-and-Ride for Urban Railway System. Sichuan: Southwest Jiaotong University; 2007.

[48] Altman E, Basar T, Jimenez T, Shimkin N. Competitive routing in networks with polynomial costs. IEEE Transactions on Automatic Control. 2002 Jan;47(1): 92-6.

[49] Yang J, Zhuang Y. An improved ant colony optimization algorithm for solving a complex combinatorial optimization problem. Applied Soft Computing. 2010 Mar 1;10(2): 653-60.

[50] Dorigo M, Maniezzo V, Colorni A. Ant system: optimization by a colony of cooperating agents. IEEE Transactions on Systems, Man, and Cybernetics, Part B: Cybernetics. 1996 Feb 26;26(1): 29-41. 
[51] Gong YC, Yang RF, Li CL. Urban Parking Allocation Model Based on Minimum Generalized Parking Costs. In: First International Conference on Transportation Engineering; 2007. p. 527-532.

[52] He S, Fan B. Generalized wardrop principle and its application in regional transportation. Transportation Research Record. 2008 Jan;2085(1): 49-56.

[53] Cho HJ, Chen YK. Finding the e-user Equilibrium Solution Using an Augmented Frank-Wolfe Algorithm. Networks and Spatial Economics. 2010 Dec 1;10(4): 473-85. 